\title{
Assessment of healing of esophageal fistulae following stent placement without complete stent removal
}

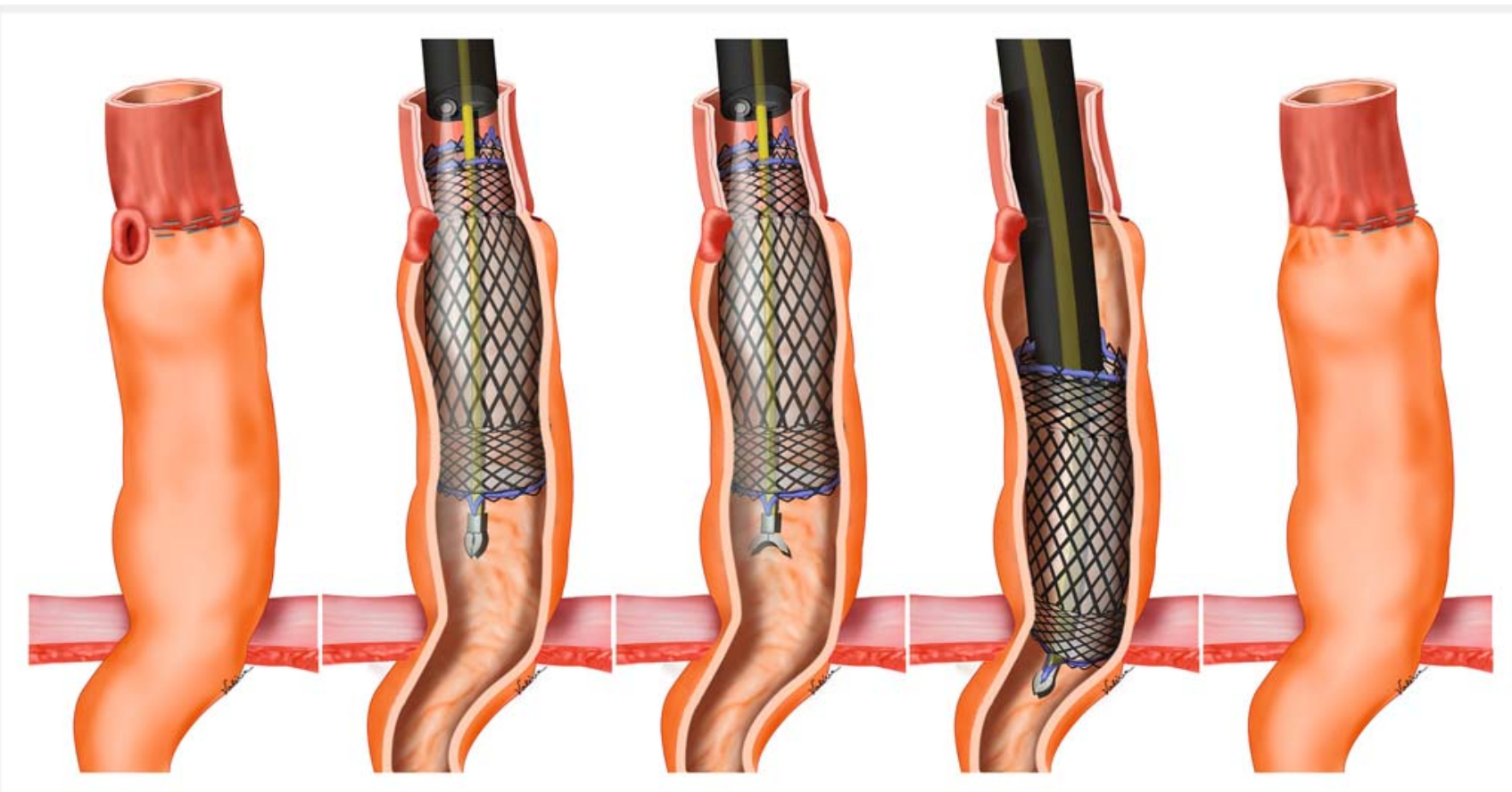

- Fig. 1 Repositioning of a fully covered, self-expandable, metal esophageal stent to assess fistula closure. From left to right: anastomotic fistula; stent in place; biopsy forceps seizing the string; dislodging the stent; the healed fistula. Source: Valéria Simões Lira

Anastomotic leaks and fistulae are among the major life-threatening post-esophagectomy complications, with incidence rates ranging from $3 \%$ to $10 \%$, increasing post-surgical mortality to about $20 \%$ [1]. The successful closure of post-surgical fistulae may be achieved by the use of fully covered, self-expandable, metal esophageal stents (SEMSs) [2]. When SEMSs are selected for treatment, stents need to be removed after 4-6 weeks. Endoscopy and contrast radiography examination may help to evaluate whether a fistula has been effectively closed [3]. If closure has not occurred, another stent should be placed at the site, followed by reassessment after another 3-4 weeks. Whereas multiple stenting may be needed for the management of persistent fistulae, this significantly impacts the final treatment costs. Fully covered SEMSs (Hanarostent; M.I. Tech, Seoul, South Korea) have been our preferred choice

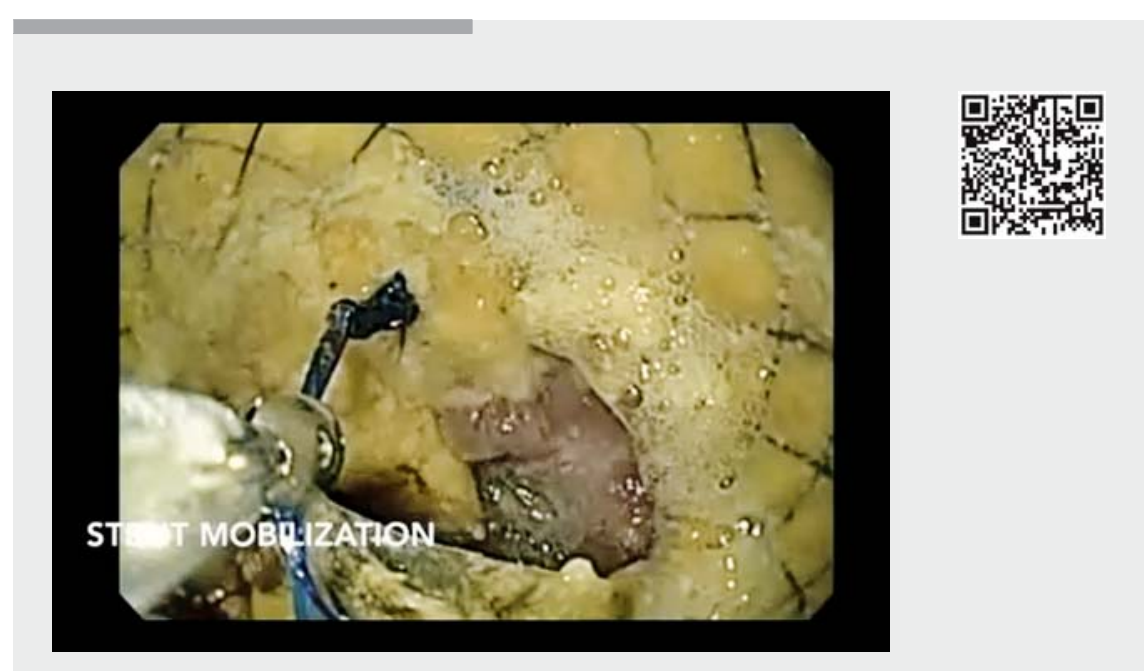

Video 1 Assessment of healing of esophageal fistula following stent placement without complete stent removal. 
for fistula management and, in order to minimize stent migration, Shim's technique (external fixation) is performed to keep the stent properly positioned.

To evaluate the success in fistula closure, we opted not to remove the stent, but rather just to move it down, away from the fistula site. Such technique involves seizing the string at the distal flange of the stent with a biopsy forceps, and then repositioning the stent further down, towards the gastric antrum, dislodging the stent from the fistulous orifice ( $>$ Fig. 1, $\triangleright$ Video 1 ).

This approach allows the fistula to be reassessed by endoscopic visualization and contrast radiography examination. If the fistula is not completely healed, the same stent may be easily repositioned, and another evaluation is performed within 2-4 weeks. As the stent is fully covered, this maneuver is easily handled with no complications. The stent is removed when a complete resolution of the fistula has been confirmed.

This technique of stent mobilization was successfully performed in five patients and it allows cost reduction, as no SEMS replacements are required per patient.

Endoscopy_UCTN_Code_TTT_1AO_2AI

Competing interests
The authors

Claudia Zitron, Adriane G. Pelosof, Eloy Taglieri, Gabriel R. Corbetta, Otavio Micelli Neto, Alvaro M. Seraphim

A.C. Camargo Cancer Center, Endoscopy, Sao

Paulo, Sao Paulo, Brazil

\section{Corresponding author}

\section{Claudia Zitron, MD}

Rua Angelina Maffei Vita 392 \# 101, Cep 01455-070, São Paulo, Brazil

Fax: +55-11-983156861

zitronc@gmail.com

\section{References}

[1] Sharma P, Kozarek R. Practice Parameters Committee of American College of Gastroenterology. Role of esophageal stents in benign and malignant diseases. Am J Gastroenterol 2010; 105: 258-273

[2] Dasari BVM, Neely D, Kennedy A. The role of esophageal stents in the management of esophageal anastomotic leaks and benign esophageal perforations. Ann Surg 2014; 259: $852-860$

[3] van Boeckel PG, Dua KS, Weusten BL et al. Fully covered self-expandable metal stents (SEMS), partially covered SEMS and self-expandable plastic stents for the treatment of benign esophageal ruptures and anastomotic leaks. BMC Gastroenterol 2012; 12: 19
Bibliography

DOI https://doi.org/10.1055/s-0043-120518

Published online: 3.11.2017

Endoscopy 2018; 50: E23-E24

(c) Georg Thieme Verlag KG

Stuttgart · New York

ISSN 0013-726X

\section{ENDOSCOPY E-VIDEOS}

https:/|eref.thieme.de/e-videos

口回 Endoscopy E-Videos is a free access online section, reporting G.: on interesting cases and new techniques in gastroenterological endoscopy. All papers include a high quality video and all contributions are freely accessible online.

This section has its own submission website at https://mc.manuscriptcentral.com/e-videos 